\title{
O HUMOR EM MOVIMENTOS SOCIAIS \\ Criatividade e informalidade nas manifestações anti-austeridade em Portugal
}

\section{HUMOR IN SOCIAL MOVEMENTS \\ Creativity and informality in anti-austerity protests in Portugal}

\section{Pedro Caldeira Pais}

Departamento de Sociologia, Escola de Sociologia e Políticas Públicas, ISCTE - Instituto Universitário de Lisboa \& Centro de Investigação e Estudos de Sociologia (CIES-IUL). Av. ${ }^{a}$ das Forças Armadas, 1649-026 Lisboa

Portugal. Email: pedromcpais@gmail.com

\section{Rita Espanha}

Departamento de Sociologia, Escola de Sociologia e Políticas Públicas, ISCTE - Instituto Universitário de Lisboa \& Centro de Investigação e Estudos de Sociologia (CIES-IUL). Av. a das Forças Armadas, 1649-026 Lisboa,

Portugal. Email: rita.espanha@iscte-iul.pt

Resumo: Esta investigação discute o papel do humor movimentos em Portugal, nomeadamente entre 2011 e 2013. Foi utilizada a Análise Crítica do Discurso para analisar cartazes de uma manifestação do Que se Lixe a Troika (QSLT) e de outra organizada pelos sindicatos, tendo-se realizado entrevistas a activistas e sindicalistas. Confirmando-se a utilização profícua de humor e criatividade no protesto do QSLT, conclui-se que se deve a um menor grau de institucionalismo, à identidade de resistência, à cultura de protesto, e à preocupação dos activistas em recriar a comunicação. São também discutidas as vantagens/desvantagens do humor na divulgação de um problema social.

Palavras-chave: humor, movimentos sociais, estratégia comunicacional, mudança social.

\begin{abstract}
This research discusses the role of humor in social movements in Portugal, between 2011 and 2013. The Critical Discourse Analysis method was used to analyze posters from Que se Lixe a Troika (QSLT) and union's protests, and interviews were conducted among activists and unionists. A profuse use of humor and informal discourse in the protest organized by QSLT is confirmed. This research concludes that this results from a lesser degree of institutionalism, an identity of resistance, an optimistic culture of protest, and the activist's concern to recreate their communication. Also discussed are the advantages/disadvantages of humor in relation to its role in publicizing a social problem.
\end{abstract}

Keywords: humor, social movements, communication strategy, social change.

\section{Introdução}

Analisando o período entre 2011 e 2013, em que se verificou uma forte contestação social em Portugal, este artigo procura explorar a forma como os diferentes movimentos 
sociais percepcionam o humor, a criatividade e a utilização de discurso informal. Concretamente, analisa-se aqui o discurso humorístico e criativo no 15 de Setembro de 2012 (15/Set), protesto convocado pelo movimento Que se Lixe a Troika - Queremos as nossas vidas (QSLT), tendo como referência comparativa o 14 de Novembro do mesmo ano (14/Nov), greve geral organizada pelas centrais sindicais, em que também ocorreu um protesto. Partindo da análise a cartazes de protesto e ao discurso dos activistas do 15/Set, procura-se, nomeadamente, debater o papel do humor dentro de um protesto de rua, pretendendo-se perceber a ligação entre tal discurso e a mudança social nesse momento histórico-político, e compreender a escolha pela utilização ou não utilização de tal conteúdo discursivo. De referir que este artigo resulta de uma investigação realizada para uma Dissertação de Mestrado, defendida em 2017 (Pais, 2017).

Uma primeira parte do artigo apresenta a contextualização teórica e a exposição de alguns conceitos relativos à temática em questão, e uma segunda a análise metodológica e as conclusões. A metodologia dividiu-se em i) análise de imagens de cartazes de dois protestos distintos (convocados por "novos" e "velhos" movimentos sociais), de modo a confirmar a utilização de mais humor e criatividade por parte dos activistas e manifestantes do QSLT, em contraste com os sindicatos; e ii) análise de entrevistas, efectuadas a cinco activistas da Geração à Rasca (GR) e do QSLT, bem como a dois sindicalistas ligados à CGTP e à sua comunicação interna e externa. Para ambas as técnicas, foi utilizada a Análise Crítica do Discurso (ACD), posteriormente detalhada.

\section{O humor, o poder e a identidade: o discurso satírico e a sua relação com a mudança social e a identidade colectiva}

No que respeita ao humor político, uma das questões sociológicas mais desafiantes é identificar a sua influência no processo democrático. Poderá ela ser medida? E, a ser o caso, de que forma poderá isso ser feito?

Normalmente são consideradas três teorias do humor, que, dentro das ciências sociais, detêm diferentes pontos de foco (Tabacaru, 2015, p. 116; Anagondahalli e Khamis, 2014, p. 2; Kutz-Flamenbaum, 2014, p. 295; Sørensen, 2014; Foot \& McCreaddie, 2006): a "teoria da superioridade", inicialmente formulada por Kant, que estipula que o riso resulta de relações de superioridade; a "teoria do alívio", desenvolvida por Freud e que vê o humor e o riso como tensões do indivíduo; e a "teoria da incongruência", associada a Platão, Aristóteles e Hobbes (Lintott, 2016), em que o discurso humorístico surge como algo que transgride determinada 'norma', sustentando-se a piada na compreensão das incoerências ali existentes. É 
natural, por outro lado, e segundo Foot \& McCreaddie (2006), que nenhuma destas teorias explique o humor de forma isolada. Assim, para esta investigação retiram-se essencialmente aspectos da teoria da superiorização e da teoria da incongruência, o que vai de encontro ao que parece ser uma maior utilização de recursos humorísticos em protestos recentes, seja através de cartazes ou até de pequenos teatros de rua (Pais, 2014; Romanos, 2012), o que pode também promover uma maior contiguidade entre humor e criatividade em âmbito de protesto (Pais, 2017).

Neste contexto, o humor pode também reflectir uma relação de forças, já que subsiste num conflito grupal, resultado de hierarquias e relações de poder (Pais, 2017), aspectos com frequência presentes, igualmente, no próprio discurso humorístico (Kuipers, 2008). E se noutras áreas académicas se considera o humor um factor relevante nas relações afectivas, pessoais ou de âmbito laboral (Fine, 1983, p. 165; Romero \& Cruthirds, 2006; Hall, 2013; Lussier, Gregoire e Vachon, 2017), é também no contexto político e social que muitas vezes se pode tornar, nos conflitos de poder, um factor de interdiscurvisidade. A sátira humorística, em especial, pode revelar-se uma estratégia útil para demonstrar falhas no comportamento ou discurso de determinados grupos e indivíduos, na medida em que, na crítica que produz, o que se distingue é a sua dimensão moral (LeBoeuf, 2007). E tal essência moral pode ser produzida por um indivíduo que se apresente anonimamente numa manifestação - isto é, não apenas por comediantes - , satirizando uma situação ou um certo problema social em que é possível identificar determinada imoralidade (Pais, 2017). Em todo o caso, o próprio humor como discurso - na sua generalidade - pode ajudar a promover uma maior consciencialização da condição humana, modificando em parte a forma como os homens percepcionam e reorganizam o mundo que os rodeia (Watson, 2014).

O humor pode envolver também o reconhecimento de uma relação hierárquica, de poder, referindo-se a mensagens, como refere Speier (1998), de baixo para cima - de "oprimidos" para "opressores" - e de cima para baixo, podendo igualmente tornar-se num utensílio de fuga (por exemplo, uma piada de um político para fugir a determinada pergunta) e, inclusivamente, de índole coerciva (Billig, 2005). Concomitantemente, as próprias relações de poder existentes em diversos momentos históricos poderão reflectir-se no discurso do humor. Veja-se, a título de exemplo, a realidade soviética, em que o conteúdo de diversas anedotas - essencialmente iguais, ao longo do tempo, na sua forma e na sua moral - criticavam de forma manifesta o poder governamental, mudando-se, para isso, os actores da anedota - por exemplo, numa sendo Lenine e, noutra, Gorbatchev - para esta continuar a ter a mesma crítica, a mesma moral e, assim se esperaria, a mesma piada (Davies, 2007). Outro exemplo é o Carnaval (Hart, 2007), evento de potencial cariz 
crítico em relação a personalidades ou instituições de poder em determinada fase histórica, política e social, demonstrando novamente a possível a relação de forças entre um grupo com menos poder, e um outro com um poder mais legitimado e com uma maior autoridade formal.

O humor em protestos e movimentos sociais

Um outro aspecto do humor é o da sua potencial contribuição para uma certa identidade colectiva em âmbito de protesto e movimento social, podendo fortalecer laços entre os próprios activistas e actores reivindicativos numa lógica de construção de afecto, solidariedade e lealdade colectiva (Hart, 2007, p. 12; Sombatpoonsiri, 2015). Ao longo dos tempos, grupos como o movimento separatista do Canadá, dos anos 80, ou os paquistaneses "Muhajir Quomi Movement", procuraram utilizar humor - muitas vezes agressivo, exagerado ou grotesco, explorando inclusivamente estereótipos religiosos ou étnicos - para mobilizar cidadãos que se encontrassem de algum modo segregados (Hart, 2007, p. 10). Um exemplo mais recente, no qual se verificou a utilização de humor e, inclusivamente, situações de cariz algo carnavalesco, é o do Occupy Wall Street (Tancons, 2014).

De facto, e como já se referiu acima, parece verificar-se, nas últimas décadas, o recurso gradual do humor e criatividade em protestos e movimentos, dos quais podem ser exemplos os Indignados, tanto em Portugal como em Espanha (Pais, 2014; Romanos, 2012). Esta tendência poderá em boa parte ser explicada pelo dimensão mediática (Hart, 2007), a que se alia o carácter do humor como ferramenta de comunicação que gera, como linguagem crítica, uma posição possivelmente mais ambígua, indirecta e circular (Gordon, 2014). Expressões humorísticas, seja através de cartazes ou teatralizações, podem ser úteis para a difusão pública da mensagem, já que o seu carácter de impressão repentina promove a que seja assinalada e reportada pelos próprios media (Romanos, 2012, p. 4). Tal relação entre humor e mediatismo será abordada posteriormente, de forma mais pormenorizada, aquando da análise dos dados qualitativos.

\section{Movimentos e institucionalização: os novos e velhos movimentos sociais}

Uma definição possível e geral de movimentos sociais pode ser a de que estes são uma rede de interacção informal entre uma pluralidade de indivíduos ou instituições, que, num conflito político ou cultural, detêm uma determinada identidade colectiva (Laer \& Aelst, 2010, p. 1147). Por outro lado, e especificando, existem, 
entre os diversos movimentos, diferenças a vários níveis. Geralmente é feita a distinção entre Velhos Movimentos Sociais (VMS) e Novos Movimentos Sociais (NMS). VMS são essencialmente movimentos de cariz operário e laboral, em que subsistem os sindicatos; desde a industrialização da sociedade, estes procuram, através da concertação social com as facções privadas e políticas, defender os direitos da classe trabalhadora (Fonseca, 2014). As grandes centrais sindicais em Portugal são a CGTP e a União Geral dos Trabalhadores (UGT), criadas ao longo dos anos 70. São estruturas hierarquizadas e mais institucionalizadas, que, através de uma negociação ou, muitas vezes, socorrendo-se a greves de trabalhadores, pressionam as instituições (privadas, políticas) a aceder ou a aproximarem-se das sua exigências.

Já os NMS detêm geralmente, em comparação, uma menor capacidade logística, menos recursos e menor capacidade de controlo no que respeita à mobilização (Fonseca, 2014, p. 261), constituindo-se, normalmente, como grupos feministas, ecologistas ou de combate à precariedade, entre muitos outros, e que tentam modificar hábitos, percepções ou padrões culturais na sociedade, promovendo pressão política ou social. Caracterizam-se por uma menor centralização logística, já que boa parte deles, segundo Fonseca (2014), vive “(...) uma existência efémera, sem perdurabilidade no tempo" (Fonseca, 2014, p. 266), e subsiste numa lógica de menor institucionalização em que o seu militante comum será essencialmente alguém “(...) urbano e preocupado com as causas cívicas e ecológicas" (Fonseca, 2014, p. 267). De realçar, porém, que pode existir sobreposição entre militantes sindicais e de NMS, sendo que vários activistas de movimentos mais recentes se encontram, paralelamente, afiliados a sindicatos.

Ora, Fonseca (2014) defende que a contribuição para a democratização pública é distinta para VMS e NMS e que os primeiros, mais activos, possuem maiores responsabilidade institucionais, que resultam, nomeadamente, na tentativa de procurar consensos legítimos com as facções com as quais se encontram em conflito (Fonseca, 2014, p. 215). De acordo com Estanque (1999), a cooptação e o progressivo enquadramento institucional são factores essenciais para serem alcançadas metas de transformação social por si propostas (Estanque, 1999, p. 86). Por outro lado, tanto VMS como NMS têm importâncias distintas quanto a alguns conceitos. Segundo Fonseca (2014), "conceitos como (...) concertação social impõem aos sindicatos um papel mais activo e responsável do que aquele que está disponível (...) para os novos movimentos sociais", ainda que, em termos mediáticos, estes últimos se possam destacar (Fonseca, 2014, p. 215). 
'Novíssimos' movimentos sociais: acontecimentos recentes de protesto

As formas tradicionais de movimentos, tal como os conhecemos hoje - nomeadamente o movimento operário - surgiram, portanto, no séc. XIX. Entretanto, têm também surgido ao longo do séc. XXI formas diferentes de fazer a acção e a reivindicação colectiva, como o QSLT, em Portugal, ou os Indignados, movimento que teve muita força em Espanha. No caso português, nomeadamente a partir de 2010, com as primeiras políticas de austeridade pelo Partido Socialista e posterior entrada da denominada 'Troika' na ingerência política e económica em Portugal, em 2011, a conjuntura política e institucional permitiu um contexto de forte protesto e reivindicação social (Fernandes, 2017).

Tendo levado à rua centenas de milhares de pessoas que protestavam políticas de austeridade e que levavam à desigualdade social, estes movimentos, como a GR e o QSLT, são também o resultado de protestos que ocorriam noutros países (Baumgarten, 2013). Como outros, por exemplo, utilizaram a seu favor novas ferramentas de comunicação - nomeadamente redes sociais - para convocar protestos e reuniões, o que introduziu uma mudança significativa na organização dos movimentos sociais em Portugal (Soeiro, 2014; Estanque, 2014). Neste período assistiu-se a uma transversalidade grande na participação de indivíduos, desde jovens sem trabalho ou em situação precária, a movimentos feministas e LGBT, não esquecendo os próprios sindicatos, que tiveram também uma participação importante nesta onda de protestos (Fernandes, 2017).

O surgimento dos novíssimos actores sociais, e tendo também em conta a sua possível filiação com sindicatos, resulta, de acordo com Fonseca (2014), da posição crítica destes em relação à via particularizada do sindicalismo e ao seu cariz mais rígido, hierárquico e burocrático, situação menos visível em movimentos novíssimos, que tendem a ser mais espontâneos e anónimos e que, inclusive - e ao contrário do que sucede nos sindicatos - , não exige pagamento de quotas (Fonseca, 2014, p. 212). Acrescenta-se a isto que novíssimos e NMS tendem a ter, em comparação com VMS, um carácter mais célere e facilitador no que concerne à comunicação existente no movimento, por um lado, e à própria ideologia, que pode assentar numa maior ambiguidade ideológica (Estangue, 2014; Pais, 2017). Estanque (2014) refere-se mesmo aos três princípios de Touraine (1985) para a explicação de movimentos sociais (Identidade, Oposição e Totalidade), defendendo que, por via de uma maior segmentação e um sentido de comunhão mais efémero no que concerne às identidades de grupo, tais princípios revelam-se hoje insuficientes para o estudo dos movimentos sociais. Segundo o autor, actualmente estes são caracterizados por ambiguidades ideológicas e pela falta de alternativa unificadora de paradigma 
(Estanque, 2014), aspectos, portanto, a ter em conta no estudo sobre os movimentos sociais da actualidade.

\section{Metodologia: Análise Crítica do Discurso}

Tanto para este artigo como para a investigação exposta em Pais (2017), foram propostas duas técnicas metodológicas de forma a estudar o tema do humor e da criatividade em movimentos e protestos: em primeiro lugar, a análise discursiva de cartazes e, em segundo, a análise de entrevistas semi-estruturadas realizadas a activistas e sindicalistas. Utilizou-se então a ACD, que, como nos diz Morgan (2010), tem em conta o contexto sociopolítico para compreender o discurso produzido pelos actores sociais, focando-se nos significados da linguagem, na relação entre esta e a realidade social e política vigente, e no papel da linguagem no que diz respeito à mudança (Morgan, 2010, p. 4). Para a construção das categorias de análise discursiva, que poderão ser vistas na Tabela 1 , foram tidas em conta três dimensões valorizadas pelos investigadores da ACD no que concerne ao discurso: (i) estrutura, conteúdo e significado; (ii) a dimensão prática discursiva, isto é, a interacção discursiva usada para comunicar crenças e significados; (iii) e a dimensão prática social, ou seja, o contexto social em que o discurso é produzido (Bryman, 2008, p. 509; Pais, 2017).

De relembrar, pois, que a análise posterior foi em parte efectuada tendo em conta o projecto de uma Dissertação de Mestrado, razão pela qual pode existir informação - nomeadamente citações ou conclusões analíticas - convergentes entre a Dissertação e este artigo.

\section{Análise discursiva de cartazes das manifestações do 15/Set e do 14/Nov: contextos distintos de discurso, humor e criatividade}

A seguinte análise foi, ao todo, feita a vinte imagens de cartazes de duas manifestações, ambas de 2012: dez imagens do protesto 15/Set, que resultou de uma convocação por parte do QSLT, e outras dez do 14/Nov, num protesto organizado pelas centrais sindicais ${ }^{1}$. Pretende-se aqui analisar um possível conteúdo de carácter mais criativo e humorístico dos manifestantes do 15/Set, em comparação com o 15/Nov. Neste capítulo em concreto, são apresentados alguns exemplos de imagens que demonstram as tendências de discurso em cada manifestação, apresentando a tabela seguinte diversas categorias de identificação que permitiram, precisamente, identificar e perceber características discursivas dos cartazes e, 


\begin{tabular}{|c|c|c|}
\hline $\begin{array}{c}\text { Identificação } \\
\text { Local } \\
\text { Conteúdo } \\
\text { Design } \\
\text { Objectivo } \\
\text { Indivíduo(s) na imagem/contexto } \\
\text { Instituição }\end{array}$ & $\begin{array}{c}\text { Número da imagem } \\
\text { que local/cidade } \\
\text { descrição da frase } \\
\text { aspectos estéticos do cartaz } \\
\text { o que pretende criticar } \\
\text { quem segura o cartaz } \\
\text { a que instituição/movimento pertence }\end{array}$ & 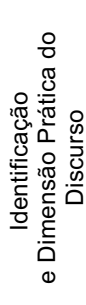 \\
\hline $\begin{array}{c}\text { Tipo de humor/linguagem } \\
\text { Significado }\end{array}$ & $\begin{array}{l}\text { linguagem produzida e, se a frase for } \\
\text { humorística, tipo de humor utilizado } \\
\text { sentido da frase/imagem }\end{array}$ & 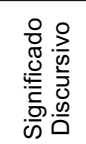 \\
\hline
\end{tabular}

Fonte: Adaptado de (Pais, 2017).

sempre que possível, do que rodeava o próprio cartaz (idade ou género de quem o segurava, a que instituição pertencia, etc.) (Pais, 2017).

Confirmando-se a hipótese proposta, verificou-se que no 15/Set houve mais cartazes com um discurso geralmente mais humorístico, criativo e informal, ao contrário de frases de carácter mais directo e repetitivo exibidas no 14/Nov. Dos cartazes analisados do 15/Set, estes possuem tendencialmente mensagens e elementos visuais de alguma forma humorísticos, dos quais se podem verificar exemplos como: "Vende-se político honesto/ Nunca foi usado"; um indivíduo que se dirige concretamente a um ministro dizendo "Relvas/ Paga as propinas"; ou ainda um jovem que ostenta um cartaz duplo, que refere: “O governo está a pôr-nos nesta figura/ Comeram-me a carne/ Sugaram-me o sangue/ É o fim/ Agora roem-me os ossos / Arre porra que é de mais", vestindo uma máscara de esqueleto e, dessa forma, complementando a sátira produzida.

Como referido em Pais (2017), a tendência de discurso visível no 15/Set pode resultar numa certa "identidade colectiva que, ainda que não direccionada ideológica e politicamente para objectivos senão de oposição, é executada num espaço partilhado, em que os indivíduos se revêem nas experiências dos outros, e em que surge a tendência para um discurso livre, em nenhum momento controlado", e que resulta numa linguagem de cariz mais informal, pessoal e criativo (Pais, 2017, p. 23).

Já no 14/Nov, de acordo com esta análise, os sindicatos apresentaram essencialmente uma linguagem reivindicativa algo repetitiva, como se verifica pelo seguinte exemplo de uma frase exibida num cartaz: "Pela defesa do acordo de emprego!/ Pela defesa dos direitos!/ Pelo aumento dos salários!/ Por mais segurança no trabalho!". Quanto a isto, Alves (2013) chega mesmo a designar de "chavões" muitas das frases de 


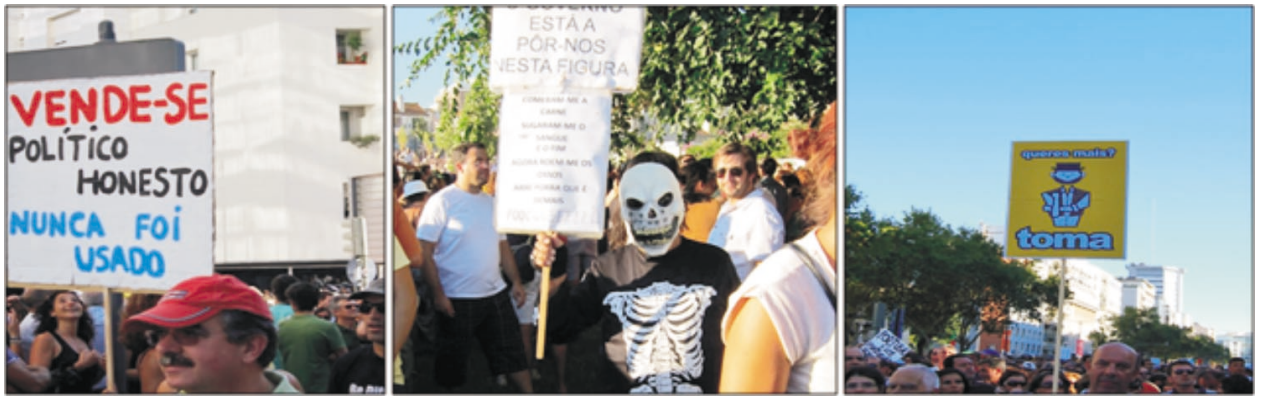

Figura 1 Cartazes de 15 de Setembro de 2012

Fonte: Blog adiaspora.com.
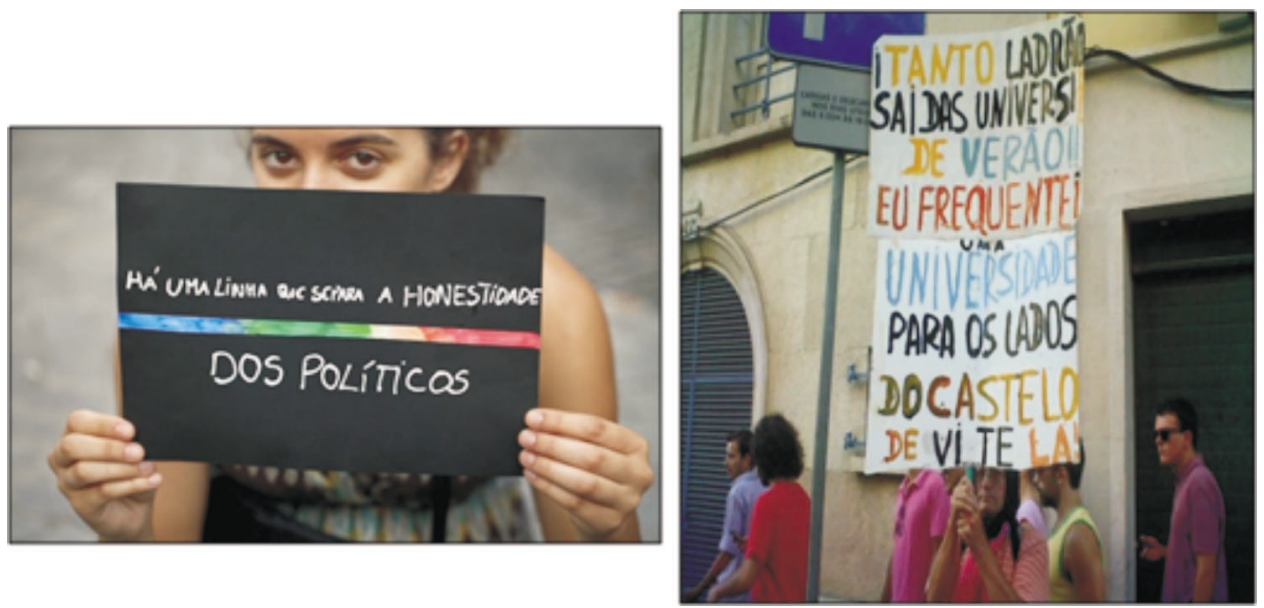

Figura 2 Cartazes de 15 de Setembro de 2012

Fontes: Sábado e Público.

índole sindical, que ainda assim, refira-se, não deixam de ser de desafio ao poder instituído (Alves, 2013). Isto significa que aparecem neste discurso elementos de formalização histórica, em que existem determinadas expectativas de discurso por parte dos trabalhadores sindicalizados e que, neste sentido, acaba por se revelar mais monótono, com poucos ou nenhuns elementos humorísticos ou identificáveis como criativos (Pais, 2017).

Atendendo agora à estética existente nos cartazes de ambos os protestos, os do14/Nov possuem na sua generalidade uma maior profissionalização em termos 

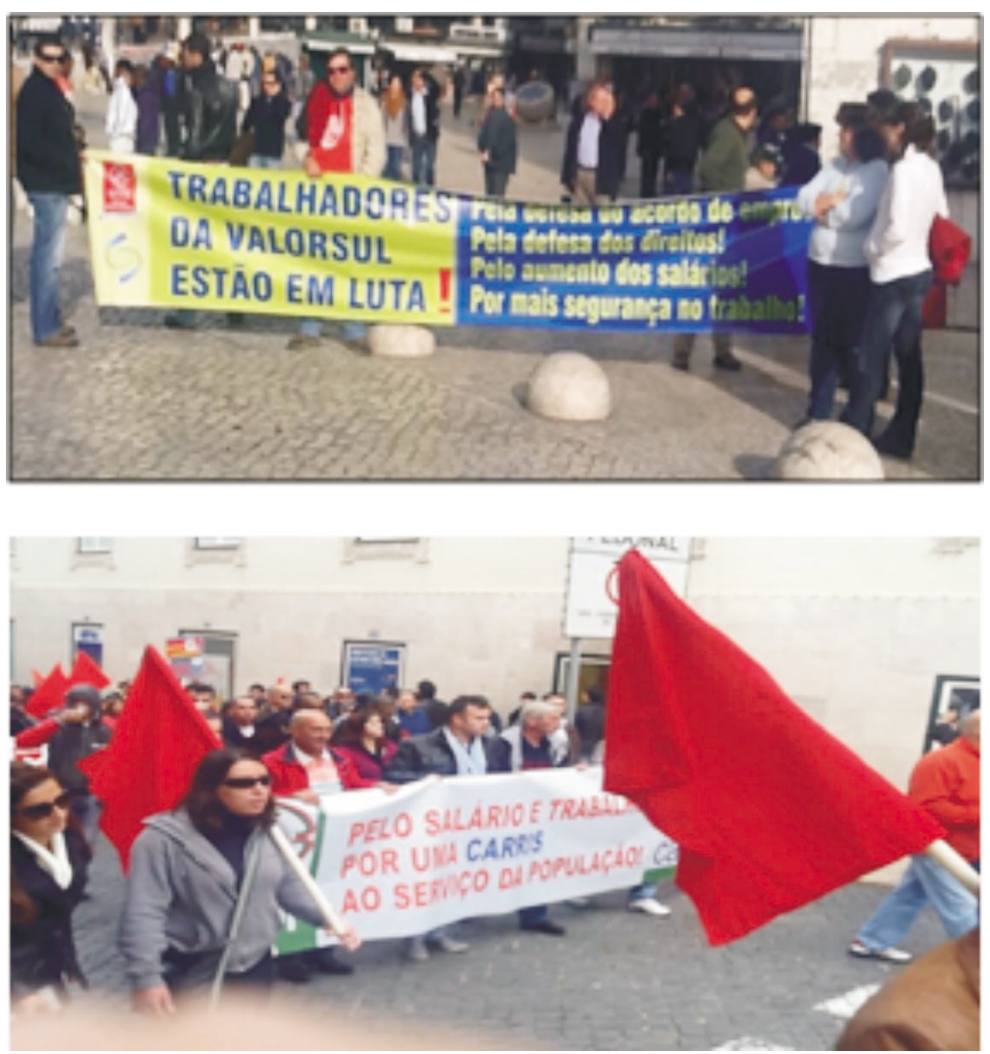

Figura 3 Cartazes sindicais da greve de 14 de Novembro de 2012

Fonte: Ephemera.

de design, maior uniformização (em termos de tamanho e na forma de apresentar o conteúdo do cartaz), o que é resultado de melhores recursos materiais - opondo-se, assim, aos menores recursos e à maior heterogeneidade visível no 15/Set.

No que diz respeita à idade dos indivíduos que exibem os cartazes, no protesto do QSLT parece ocorrer uma predominância de jovens, sendo que existe também um número considerável de manifestantes com mais idade. Precisamente, uma das imagens apresenta uma mulher pertencente a uma faixa etária mais avançada a segurar um cartaz que refere: "Tanto ladrão sai das universidades de verão! Eu frequentei uma universidade para os lados de Castelo de Vi... te lá!" Isto é assim revelador da diversidade etária na manifestação, dados corroborados, nomeadamente, por uma investigação de carácter quantitativo (Cardoso et al., 2016). Por outro lado, o 14/Nov revela uma tendência diferente, retratando-se, através da 
análise, uma maioria de indivíduos de meia-idade e, neste sentido, uma maior homogeneidade etária (Pais, 2017).

\section{O carácter institucional dos movimentos sociais e sindicais e a sua influência discursiva}

De forma a compreender melhor a envolvência social, política e reivindicativa existente em Portugal entre 2011 e 2013, nomeadamente, e tendo especial incidência nos movimentos e protestos que ocorreram nessa fase, foram realizadas 7 entrevistas semi-estruturadas, cinco a activistas ${ }^{2}$ e duas a sindicalistas ${ }^{3}$. A contribuição dos entrevistados para a investigação revelou-se, assim, importante e fundamentada, na medida em que os cinco activistas participaram activamente na organização de diversas reivindicações, nomeadamente do QSLT, e os dois sindicalistas eram, neste período, elementos com responsabilidade nas áreas da comunicação e organização da CGTP.

As entrevistas permitiram perceber diversos aspectos, em especial no que respeita à organização dos movimentos e aos seus objectivos em termos de reivindicação, aos recursos humanos e materiais disponíveis, à responsabilidade institucional, ou ainda a estratégia comunicacional seguida tanto pelos sindicatos como, nomeadamente, pelo QSLT e a GR.

Precisamente, pretende-se nesta investigação relacionar o discurso com o institucionalismo, sendo o institucionalismo de uma organização - e a sua comunicação - resultado de aspectos como a relação institucional que possui com as entidades políticas, o público-alvo para o qual comunica, as consequências as suas acções têm no espectro político e social, a sua responsabilidade pública, os recursos humanos e materiais que tem disponível, ou ainda a sua capacidade para mobilizar cidadãos (Pais, 2017).

No seguimento do que foi já referido anteriormente, ocorre em Portugal, de uma forma geral, uma diferença de graus de institucionalização entre os sindicatos e, no caso em concreto, estes movimentos novíssimos. No caso do QSLT, e tendo em conta as palavras de Pedro, elemento dos Precários Inflexíveis (PI) e um dos principais organizadores do QSLT, quando existia alguma reunião que serviria para decidir aspectos importantes para o movimento, os participantes estavam completamente livres para decidir, não havendo necessidade de reunir com os PI para discutir propostas (Pais, 2017). Esta informalidade não existia nos centros sindicais, como de resto nos diz Cristina, uma activista das Panteras Rosa (PR): 
“Nós [GR e QSLT] não fomos a reuniões com o governo, independentemente da posição de forças que tínhamos com as pessoas que trazíamos à rua. E os sindicatos tinham. Portanto, a partir do momento em que o protesto chega a uma base de negociação, ou a uma base de oposição em gabinetes, nós deixamos de existir, e passa a existir o sindicato." [Cristina, das Panteras Rosa] (Pais, 2017, p. 27)

Quando a isto, tenha-se também em conta a opinião de Sandra, activista dos PI, que se referiu à liberdade institucional que estes activistas detêm:

“(...) [Nos protestos dos PI] tu podes dizer asneiras, se quiseres. Não estás a pôr em causa nenhuma organização, não estás a ferir nenhuma susceptibilidade." [Sandra, dos Precários Inflexíveis] (Pais, 2017, p. 27)

Desta forma, a menor organização e centralização institucional do QSLT como movimento, apesar do seu papel como elemento de pressão social e política, criava condições para uma menor influência dentro das plataformas formais e, igualmente, para uma estratégia institucional menos delineada e, por conseguinte, menos consistente a médio e longo-prazo.

E no que respeita à comunicação, havia assim estratégias e apelos diferentes entre os sindicatos e estes movimentos, sendo que Sandra revela mesmo que os "sindicatos têm uma mensagem institucional", o que, para si, o resulta num discurso mais formalizado (Pais, 2017). Assim, é ao nível do discurso que se revelam grandes diferenças entre associações como os PI ou as PR, incluindo movimentos como o QSLT, e os sindicatos, havendo por exemplo da parte destes, segundo Leonor - activista dos PI - , uma certa monotonia institucional, resultado de terem "uma imagem a manter" no âmbito público e político. A mesma activista defende que é difícil as instituições sindicais se actualizarem ao nível do discurso, na medida em que são organismos demasiado grandes que se estabeleceram num "espaço que é deles". Já Miguel, organizador da Maré da Saúde do QSLT, refere que os sindicatos procuram "capitalizar os trabalhadores mais velhos, a trabalhar há mais tempo, enquanto os protestos do QSLT e dos acampados são dirigidos sobretudo aos jovens." É aqui introduzida a questão do público-alvo para a comunicação - no caso, a tentativa de falar para um público mais jovem - , aspecto que será explorado mais à frente. De resto, Cristina, activista das PR, refere que um elemento pertencente a um sindicato sabe que "vai defender aquela posição, aquela orientação, aquelas palavras de ordem." É por isso importante, para os elementos de um sindicato, que exista uma centralização ao nível da comunicação e dos parâmetros ideológicos (Pais, 2017).

Da parte dos sindicatos, contudo, é mais valorizada a questão de uma maior complexidade institucional tendo em conta uma linha geral para, por exemplo, 
uma greve geral ou um protesto. Segundo Ângela, elemento da área de Informação e Propaganda Sindical (IPS) da CGTP, para a constituição dessa estratégia a central sindical, antes de tudo, ouve a sua 'estrutura de base', ou seja, os trabalhadores associados a cada sindicato, referindo:

“(...) [A estrutura de base] vai-nos dizer 'nós temos aqui luta para estas matérias, são estas as nossas reivindicações, são estas as palavras de ordem que nós estamos a pensar', e o que a CGTP faz é ouvir em conjunto as suas estruturas de base e então aí tomar uma decisão." [Ângela, da área da Informação e Propaganda Sindical, da CGTP] (Pais, 2017, p. 28)

Acrescentando a isto, José, um dos coordenadores da União dos Sindicatos de Lisboa (USL), refere que é o organismo central que define a estratégia organizacional, os percursos e as palavras de ordem que surgem do debate existente na CGTP. De qualquer forma, pois, existe assim - e em contraste com o que sucede em movimentos como o QSLT - uma organização centralizada e uma comunicação e ideologia mais homogéneas e que atravessam os diferentes sectores do organismo. Neste sentido, José declara que "nós [sindicatos] temos responsabilidade para com aqueles que mobilizamos e conhecemos quem mobilizamos", referindo-se às expectativas institucionais que, inevitavelmente, os sindicatos têm de ter em conta (Pais, 2017).

Do lado de movimentos como o QSLT, portanto, existe uma menor responsabilidade institucional, criando condições para uma comunicação mais liberta, nomeadamente em protestos de rua - acontecimentos em que a sua voz será, de uma forma geral, mais ouvida; já do lado dos sindicatos, verifica-se um maior comprometimento institucional em relação às expectativas dos seus associados e da sociedade em geral, em especial das entidades políticas, com as quais deve coexistir formalmente. Estes diferentes graus de institucionalização, como se viu, resultam em diferentes formas de abordar o discurso, criando, com maior ou menor evidência, determinados constrangimentos.

\section{Objectivos reivindicativos: o turbilhão de indignações da Geração à Rasca e do Que se Lixe a Troika}

Num contexto de manifestação, os seus participantes tendem a concordar de uma forma geral com o que ali é reivindicado, construindo também dessa forma uma determinada identidade colectiva. Tal força identitária - nomeadamente no que diz respeito à sua longevidade e cingindo-se ao contexto de um movimento - relaciona-se em grande parte com os objectivos e o planeamento que é proposto. No 
caso do QSLT, e de acordo com Cristina, das PR, este tinha dois objectivos prioritários: fazer cair o governo e estabelecer-se como uma frente de oposição à Troika. Distinguem-se assim objectivos de contra acção, resistência e tentativa de pressão (numa identidade clara de oposição), ao invés de priorizar um planeamento mais construtivo e que procurasse uma solução colectiva que detivesse maior consistência (Pais, 2017).

Miguel refere-se precisamente à ideia de uma identidade de resistência e, segundo ele, à necessidade de filtrar, dirigir e estruturar a crítica reivindicativa:

“Eu acho que quando se tenta organizar alguma coisa com muitas pessoas, tenta-se diminuir ao mínimo o objectivo (...), nomeadamente quando se revela uma indignação pouco estruturada ou pouco orgânica." [Miguel, do Sindicato dos Médicos e da Maré da Saúde] (Pais, 2017, p. 32)

Argumenta-se, assim, que tal 'indignação pouco estruturada', nas palavras de Miguel, poderá ter contribuído para a existência de um discurso de carácter mais informal e disperso. Não se quer com isto dizer, contudo, que a existência desse discurso retire valor político e reivindicativo à mensagem produzida; não obstante, e segundo vários dos activistas, haveria a tendência clara para que tais mensagens políticas não tivessem o peso de uma estrutura mais formalmente colectiva e pensada (Pais, 2017). E por não existir nas manifestações e movimentos da GR e do QSLT um objectivo político e colectivo quando ao rumo a seguir - aliado ao descomprometimento institucional da maioria das pessoas que participou nestes protestos - , o discurso nas manifestações, nomeadamente no que respeita aos cartazes exibidos, surgia tendencialmente mais disperso e pouco congregado (Pais, 2017).

Precisamente, os activistas aperceberam-se dessa dispersão do discurso geral após a primeira grande manifestação do QSLT, e procuraram formas de resolver essa questão. A solução encontrada foi a de recriar as 'marés', ideia que surgiu das manifestações de Madrid, para o protesto de 11 de Março de 2013, a outra grande manifestação do QSLT (Camargo, 2014). O objectivo era dividir os manifestantes em áreas de trabalho ou de interesse (saúde, educação, comunidade LGBT, entre outras), de forma, segundo Miguel, a "reunir todos os sectores que estavam a ser afectados pelas políticas de austeridade e tentar mobilizar as pessoas em relação àquilo que lhes era mais próximo." (Pais, 2017, p. 33). Apesar de, segundo alguns dos activistas, as 'marés' não terem tido o sucesso e a longevidade esperada, isto foi revelador da tentativa em que a reivindicação do movimento evoluísse e, de alguma forma, organizasse as mensagens reivindicativas em grupos menores, mais exclusivos, para também atingir alvos mais definidos. 
Ainda no que diz respeito a este tema, e tendo especialmente em conta o número consideravelmente grande de indivíduos que o movimento conseguiu convocar para as ruas, Cristina salienta a falta de um processo pós-protesto, que ajudasse a dirigir a massa de indignação para uma solução mais consistente e menos efémera:

“No dia seguinte a um protesto [da GR ou do QSLT] havia uma espécie de balão social que desinchava. E, de alguma forma, isso permitiu também que o governo não caísse, porque não havia uma continuidade diária de oposição. O protesto esvaziava essa oposição um bocadinho, porque as pessoas sentiam-se de alguma forma politicamente envolvidas, representadas ou capazes de ser ouvidas, o que na realidade não se verificava." [Cristina, das Panteras Rosa] (Pais, 2017, p. 33)

Desta forma, surgiu do 15/Set, nomeadamente, um discurso menos agregado, embora com uma maior liberdade de expressão, razão pela qual, argumenta-se, é em parte produzido um discurso tendencialmente pautado por características criativas e humorísticas.

\section{O ambiente dos protestos e o discurso: relação e influência}

Através das entrevistas foi também possível perceber a posição dos movimentos novíssimos em relação à cultura de protesto que pretenderam promover, nomeadamente na fase entre 2011 e 2013, e que essencialmente se focava, de acordo com os activistas, em recolher dos participantes emoções e comportamentos mais positivos (Pais, 2017). Em parte de forma deliberada, isto contrasta directamente com a tendência dos sindicatos em secundarizar a dinâmica de protesto em prol de um trabalho contínuo que, e de acordo com José, elemento da coordenação da União dos Sindicatos de Lisboa (USL), valoriza o contacto directo com os trabalhadores, tanto em reuniões nos locais de trabalho como em plenários, referindo este, aliás, que a USL e a CGTP nunca se deslumbraram com "grandes eventos com grandes coisas." (Pais, 2017) Por esta razão, e até antes de movimentos como o QSLT, organizações como os PI e as PR procuraram, nas suas manifestações, introduzir elementos lúdicos como música e cartazes que revelassem algum humor, com o objectivo de, precisamente, procurar que suceda naqueles espaços reivindicativos uma maior liberdade de discurso e de comportamento (Pais, 2017).

Os activistas falam assim dos protestos do QSLT como espaços onde se procurava algo de diferente. Pedro, dos PI, fala mesmo destes como "espaços de reinvenção", nos quais os indivíduos - muitos deles sem passado reivindicativo podiam partilhar e criar empatia com outros manifestantes: 
"Procurámos sempre que uma manifestação fosse uma coisa divertida para as pessoas, e que as palavras de ordem tivessem coisas (...) fortes e outras cómicas." [Pedro, dos Precários Inflexíveis]

Isto resultava também numa identidade mais familiar, já que, segundo Leonor, as pessoas sentiram que "podiam tornar aquilo seu, sem receio, e que estavam a contribuir de certa forma" (Pais, 2017). De acordo com o que se tinha já observado em Pais (2014), de facto existiu aqui, de forma clara, a inclinação para uma cultura de protesto mais positiva, o que, de resto, não é alheio à tentativa destes movimentos em dirigir o seu discurso a um público mais jovem e que é, eventualmente, mais tolerante em relação a um comportamento com características mais informais.

Mas, de uma forma geral, podem ser retirados aspectos positivos deste tipo de cultura de protesto que não se cingem apenas à comunicação a um público-alvo em concreto. Como referido em Pais (2017), pode nomeadamente "ajudar a estabelecer interactividade entre os participantes, criando empatia social e contribuindo para a construção de uma certa identidade colectiva, ainda que se possa revelar efémera" (Pais, 2017, p. 35). A procura por este tipo de ambiente reivindicativo, portanto, foi um factor importante para a existência de espaços onde existiu uma maior partilha e, essencialmente, uma maior liberdade discursiva.

\section{O processo criativo: espaços para a criatividade e o humor}

A procura por uma cultura de protesto mais informal encontra-se intimamente ligada à dimensão tratada neste capítulo, que diz respeito ao processo criativo não apenas para os protestos, mas para qualquer outro tipo de manifestação, como por exemplo uma pintura num mural. E tal processo, naturalmente, ocorre na preparação para estes eventos. O activista Pedro refere-se, neste cado, aos PI, nomeadamente na fase do QSLT, como um espaço associativo para criação e envolvimento de ideias, tendo até em conta a limitação de recursos materiais por parte dos activistas:

“Os Precários sempre foram um espaço muito importante de convívio e preparação de materiais. Isto é, ir arranjar cartões aos supermercados, fazer os cartazes, pintar, e depois ficávamos 20 pessoas a escrever algumas coisas acutilantes do ponto de vista político, outras parvas. (...) Acho que nós sempre pensámos nisto como um espaço que envolve as pessoas na cena do 'faz o teu próprio cartaz'." [Pedro, dos Precários Inflexíveis] (Pais, 2017, p. 35-36)

Por outras palavras, as reuniões colectivas tendo em vista um processo criativo, pressupõem, nas palavras do activista, uma crescente liberdade e contribuição 
individual, o que acaba por resultar num espaço de invenção e reinvenção. Novamente, pois, é aqui procurado - como na cultura de protesto que é promovida que estes sejam espaços ou encontros maioritariamente informais e sem qualquer tipo de controlo. Leonor, também dos PI, refere-se precisamente a isso ao dizer que a criação de palavras de ordem a utilizar nas manifestações do QSLT aconteceriam "se calhar numa noite à volta de copos", em que as pessoas dizem "coisas para o ar", o que resulta, segundo a mesma, numa linguagem mais informal, porque o ambiente em que existe este processo é igualmente informal (Pais, 2017, p. 36).

Um outro factor importante para a comunicação deste tipo de movimentos, e que se relaciona com a comunicação que quer efectuar, é a parte visual. Dando-se aqui o exemplo das pinturas em murais de rua, manifestações relativamente frequentes no período em análise, era importante, segundo Sandra, dos PI, que a mensagem visual exposta num mural criasse impacto para as pessoas que passariam pela rua. Ou seja, havia deliberadamente uma preocupação estética em passar uma mensagem crítica que, aos olhos dos indivíduos, criasse empatia e, deste modo, ajudasse em parte ao desenvolvimento de uma maior consciencialização e identidade colectiva.

Por outro lado, deve-se ter em conta que, na compreensão do fenómeno do QSLT e do 15/Set em particular, existe sempre a dificuldade de se estar a analisar um movimento ou uma convocação de massa, já que - e na percepção dos próprios activistas - grande parte dos manifestantes não pertenceriam, de modo formal, a qualquer organização ligada de algum modo a práticas reivindicativas. Precisamente, esta situação é assinalada por Cristina:

“(...) [No QSLT] as 20 pessoas que debatiam eventualmente a faixa ou a comunicação não conheciam de lado nenhum as 500 mil pessoas que saíram à rua. Estas juntavam-se à causa, mas traziam as suas próprias palavras de ordem, os seus próprios cartazes, a sua própria indignação..." [Cristina, das Panteras Rosa] (Pais, 2017, p. 37)

No entanto, a lógica deliberadamente informal existente nos grupos activistas parece interligar-se com uma cultura de protesto precisamente mais informalizada, criativa e humorística, aspectos visíveis em grande parte dos cartazes trazidos à rua pelos indivíduos reivindicativos.

Mais uma vez, é também interessante perceber as diferenças entre o processo de planeamento (criativo ou não) entre estes movimentos e os sindicatos. Estes últimos possuem, em comparação, uma maior capacidade para, por exemplo, criar e distribuir panfletos ou cartazes, sendo que, de acordo com Ângela, do IPS, este processo resulta de uma reprodução central deste tipo de materiais que são depois enviados para as uniões (organismos sindicais regionalizados) e que são 
posteriormente distribuídos pelos diversos sindicatos. Concomitantemente, e de acordo com José, os sindicatos procuram também valorizar mais o conteúdo da mensagem política que se quer fazer passar, secundarizando a procura por inovações e criatividades discursivas, o que, aliás, poderia até desvirtuar em parte o conteúdo e a seriedade institucional de tal mensagem. Quanto a isto, José diz mesmo que, para os sindicatos, "a capacidade de imaginação tem de estar um pouco sujeita e subordinada a passar a mensagem política." (Pais, 2017, p. 38). A clareza da mensagem, portanto, é valorizada acima de qualquer ambiguidade discursiva.

\section{A utilização do humor e a sua relação com a mudança social: utilidade, funções e identidade}

A relação do humor com a mudança social não é um tema novo ou, como já se viu, que se cinja à realidade portuguesa no período em análise. Um exemplo interessante é o de um partido político húngaro - denominado 'Cão com Duas Caudas' - que organizou uma manifestação em Budapeste com cerca de 2 mil participantes, na qual eram exibidos cartazes como: 'Chega desse absurdo chamado democracia", ou "Abaixo a imprensa, abaixo a educação"4 (Pais, 2017, p. 38). Aqui pode ser introduzida a questão da dimensão mediática de tal manifestação. Isto é, se por um lado será difícil perceber as consequências políticas e sociais que uma manifestação irónica como esta obteve no contexto político-social em que se envolve, por outro lado parece sensato dizer que a mesma possuiu, por via da sua originalidade, uma capacidade mediática internacional (chegando, por exemplo, a ser notícia em Portugal) que um outro tipo de protesto, mais formalizado, possivelmente não possuiria.

Como referido em Pais (2017), no contexto de uma manifestação isto remete ao humor duas dimensões: primeiro, um carácter satírico e denunciador; e, segundo, a capacidade de atrair, por via de um discurso informal e aparentemente inadequado à situação envolvente, não apenas a atenção de outros manifestantes, mas também a atenção da própria comunicação social.

No que diz respeito à tentativa de atrair outros manifestantes, e como se viu anteriormente, é deliberada, por parte dos activistas, a concepção de cartazes ou mensagens atractivas, tanto no conteúdo como na forma, o que em grande parte, pois, também se deve à tentativa em falar para um público mais jovem. Neste âmbito, Leonor, dos PI, refere-se aqui às vantagens do humor e de uma forma discursiva mais original, nomeadamente na criação de uma maior partilha identitária entre os jovens: 
"Há coisas que podem ser engraçadas, que podem ser feitas, que devem ser feitas, porque isso também chama a atenção, e chama a atenção de um grupo (...), que são os jovens. Porque raramente a comunicação que vemos é feita para jovens; é feita para velhos de setenta anos que viram sempre aquilo... não é feito para as pessoas." [Leonor, dos Precários Inflexíveis] (Pais, 2019, p. 39)

Cristina também se refere ao humor e às suas vantagens, insistindo na comparação com os sindicatos e a comunicação produzida por estes:

“Acho que é muito eficiente. Acho que é muito mais fácil tu ríres-te com a política e, a partir daí, criares uma oposição, uma indignação, algo que te relaciona com a crítica a algo que queres combater, do que utilizares, sei lá, as frases específicas nos sindicatos: 'Melhores salários!' Sim, nós queremos melhores salários..." [Cristina, das Panteras Rosa] (Pais, 2017, p. 39)

Reforça-se aqui, portanto, a questão da identidade e do seu reforço através de uma oposição que detém a capacidade de 'rir' perante o comportamento e o discurso dos outros. Assim, num contexto de manifestação o discurso humorístico pode ajudar a criar uma dinâmica de identidade colectiva, compartilhando, de forma eficaz, indignações ou ideias cujas referências - ou seja, propriedades para perceber o que faz da piada uma piada - se encontram partilhadas pela maioria dos indivíduos do grupo (Pais, 2017).

Cingindo-nos agora ao poder de divulgação - inclusive através dos media do discurso humorístico, importa referir que, ainda antes de 2010, os PI, por exemplo, procuravam realizar acções simbólicas que, muitas vezes, detinham características humorísticas (e.g., atirar milhares de pequenos papéis, muitos deles com frases irónicas acerca da precariedade, no meio de um centro comercial). Isto era feito com o objectivo de chamar à atenção os indivíduos 'anónimos sobre a situação', procurando-se, dessa forma, desenvolver um processo de consciencialização acerca do tema da precariedade, que, naquela fase, era um conceito pouco interiorizado na sociedade portuguesa (Pais, 2017). No entanto, à medida que tal processo de consciencialização foi avançando e se tornando mais eficaz, a forma de abordar o tema também modificou. Segundo Sandra, dos PI, após a maior interiorização da questão da precariedade, esse tipo de acções simbólicas não ajudariam à discussão do problema:

“Quer dizer, hoje em dia toda a gente sabe... as pessoas têm noção do que é a precariedade (...). Não consigo imaginar humor associado a isto, porque é uma oportunidade incrível o que está a acontecer, tens que ser claro. Podes ainda ter coisas informais (...), mas tem de ser informação clara, não é com torneados e ironias." [Sandra, dos 
Precários Inflexíveis] (Pais, 2017, p. 40)

Pode assim dividir-se um processo de consciencialização como este em dois aspectos: na divulgação e compreensão pública de um problema social, contexto em que o humor e as acções simbólicas podem deter uma função relevante; e no âmbito formal em que o problema é passível de ser solucionado (e.g., discutido no Parlamento), dentro do qual a utilidade do humor diminui (Pais, 2017). Por outras palavras, o discurso humorístico no contexto reivindicativo parece ser mais útil quando consegue dar voz a indivíduos que se encontram de algum modo marginalizados, nomeadamente no que concerne à sua pouca influência em plataformas formais, usando-se desse tipo de discurso para chamar a atenção para determinada situação (Pais, 2017). Como referido em Pais (2017), “(...) a partir do momento em que essa batalha [da progressiva consciencialização] é ganha, o humor, segundo conclusões retiradas das entrevistas, pode adquirir para alguns dos activistas, até, uma dimensão perigosa: a de deslegitimar a seriedade do problema, se este se encontra já num patamar de decisão" (Pais, 2017, p. 41). Acima de tudo, pois, parece tratar-se de falta de utilidade, e, por via disso, de falta de eficácia relativamente à mudança e à consciencialização. Por outras palavras, a função do humor pode deixar de existir, abrindo espaço para outras formas de comunicação, de âmbito mais formal e institucional. Como também referido em Pais (2017), “(...) mais do que acções simbólicas humorísticas e criativas, é a clareza da mensagem que, a partir desse momento, se revela primordial" (Pais, 2017, p. 41).

Novamente, pois, é interessante analisar o papel dos sindicatos e a sua responsabilidade institucional como influente no discurso que produz. Ângela admite mesmo que o humor pode ter uma influência interessante no que diz respeito a um determinado processo de reflexão; no entanto, defende que o discurso humorístico pode acabar por desvirtuar a clareza da mensagem que se quer fazer passar:

\footnotetext{
“Nós temos que falar para todos, aqueles que conhecem mais, conhecem menos, que percebem mais, que percebem menos... A ironia serve por vezes propósitos extraordinários (...), mas a nível de clareza de passagem de mensagem não sei se será o mais positivo." [Ângela, da área da Informação e Propaganda Sindical, da CGTP] (Pais, 2017, p. 41)
}

José, que, como se viu, corrobora também com esta opinião, admite a falta de aposta, por parte dos sindicatos, num discurso mais criativo e humorístico, sublinhando, porém, a vantagem que tal discurso poderá ter na discussão de um problema e chegando a referir que, no futuro, poderia existir um maior investimento nesse tipo de linguagem. 
Nesta investigação, surgem assim algumas conclusões sobre a utilidade do humor em âmbito de protesto e que vão ao encontro, em parte, ao que é retratado por Romanos (2013) no estudo que efectuou sobre os Indignados em Espanha. Como também referido em (Pais, 2017), a mais frequente utilização de humor nas manifestações em Portugal ajudou (i) à divulgação mediática de problemas do âmbito público e social; (ii) a alimentar uma cultura de protesto mais pacifista (Pais, 2014), ainda que com linguagem crítica e reivindicativa; (iii) a que os activistas sentissem a necessidade de reinventar a sua comunicação; (iv) à criação de uma oposição baseada num discurso de ridicularização do poder institucional; (v) e destaque ainda para o auxílio que tal discurso, fosse dirigido para a oposição ou para a sua própria situação individual ou social, deu à criação de uma identidade colectiva de resistência e oposição relativamente ao poder institucional (Pais 2017, p. 42).

\section{Considerações finais}

É importante referir que esta análise se cinge ao período entre 2011 e 2013 em Portugal, e tem em conta a especificidade do momento histórico, político e social que o país atravessava. Desta forma, não significa que as conclusões aqui expostas se verifiquem noutros contextos. Não obstante, são visíveis as propensões colectivas e estruturais que apontam para uma maior liberdade discursiva e humorística, por parte dos actores reivindicativos, mediante a existência e o grau - maior ou menor - dos conceitos aqui tratados, como o da institucionalização. No contexto aqui retratado, pois, o humor demonstrou que pode ter um papel importante no que concerne à divulgação, ao mediatismo e à partilha identitária, dimensões às quais se alia uma forte propensão para a existência de elementos de criatividade. De resto, o humor poderá ser visto como uma ferramenta comunicacional útil não apenas para a divulgação de determinada mensagem, mas também para uma certa agregação grupal, podendo ser melhor aproveitada, em especial, pelos sindicatos, que poderiam aliar a linguagem sindical - importante para a sua identidade - com alguma informalidade discursiva, o que ajudaria, nomeadamente, no contacto com a população mais jovem.

\section{Notas}

Por decisão pessoal, os autores do texto não escrevem segundo o novo acordo ortográfico. A investigação exposta no artigo resultou de um trabalho realizado para uma dissertação de Mestrado em Comunicação, Cultura e Tecnologias da Informação, do ISCTE-IUL. 
1 Todas as imagens foram retiradas da Internet (arquivos, revistas/jornais, blogues).

2 Três dos activistas pertencem aos Precários Inflexíveis, uma às Panteras Rosa e outro trata-se de um dos organizadores da Maré da Saúde, um movimento dentro do QSLT.

3 Os sindicalistas são elementos da estrutura da CGTP, pertencendo Ângela à área da Informação e Propaganda Sindical, e José à coordenação da União dos Sindicatos de Lisboa.

4 Fonte noticiosa: https://goo.gl/jWuwye

\section{Referências bibliográficas}

Alves, T. C. (2013). Média, movimentos sociais e democracia participativa: As mensagens políticas nos cartazes da manifestação de 15 de Setembro de 2012. Estudos em Comunicação, 14, 123-136.

Anagondahalli, D. \& S. Khamis (2014). Mubarak Framed! Humor and Political Activism before and during the Egyptian Revolution. Arab Media \& Society, 19, pp. 1-17.

Baumgarten, B. (2013). Geração à Rasca and Beyond: Mobilizations in Portugal After 12 March 2011. Current Sociology, 61(4), 457-473.

Billig, M. (2005). Laughter and Ridicule. Towards a Social Critique of Humour. London, Sage. Bryman, A. (2008). Social Research Methods. Oxford, OUP.

Camargo, J. (2014). Não à Troika em Portugal: movimentos e resistências. Ágora, 1(2), 135-154. Doi: http://dx.doi.org/10.6035/Kult-ur.2014.1.2.7

Cardoso, G. \& Mendonça, S. \& Paisana, M. \& Pais, P. C. \& Sousa, J. (2016). Notícias, 'Fake News' e Participação Online. OberCom, Investigação e Saber em Comunicação. Retirado de https://obercom.pt/wp-content/uploads /2017/02/2017_OBERCOM_noticias-fake-news-participa\%C3\%A7ao-online.pdf

Estanque, E. (1999). Acção colectiva, comunidade e movimentos sociais: para um estudo dos movimentos sociais de protesto público. Revista Crítica de Ciências Sociais, 55, 85-111.

Estanque, E. (2014). Rebeliões da classe média? Precariedade e movimentos sociais em Portugal e no Brasil (2011-2013). Revista Crítica de Ciências Sociais, 103, 53-80. Doi: http://dx.doi.org/10.4000/rccs.5540

Davies, C. (2007). Humour and Protest: Jokes under Communism. International Review of Social History, 52, 291-305. DOI: 10.1017/S0020859007003252

Fernandes, T. (2017). Late Neoliberalism and Its Disontents: The Case of Portugal. In Della Porta D. \& Andretta M. \& Fernandes T. \& Romanos E. \& O'Connor F. \& Vogiatzoglou M., Late Neoliberalism and Its Discontents in the Economic Crisis: comparing social movements in the European periphery (pp. 169-200). Cham, Springer.

Fine, G. A. (1983). Sociological Approaches to the Study of Humor. In Paul E. McGhee \& Jeffrey H. Goldstein (Eds.), Handbook of Humor Research (pp. 159-181). New York, Spenger-Verlag.

Fonseca, D. (2014). O papel das Relações Públicas na modernização dos sindicatos portugueses. Novos e velhos movimentos sociais. Tese de Doutoramento em Ciências da Comunicação, Covilhã, Universidade da Beira Interior. 
Foot H. \& M. Mcreaddie (2006). Humour and Laughter. In Hargie O. (Ed.), The Handbook of Communication Skills (pp. 293-322). London, Routledge.

Gordon, M. (2014). Humor, Laughter and Human Flourishing. A Philosophical Exploration of the Laughing Animal. London, Springer.

Hall, J. A. (2013). Humor in Long-Term Romantic Relationships: The Association of General Humor Styles and Relationship-Specific Functions with Relationship Satisfaction. Western Journal of Communication, 77(3), 272-292. Doi:

Hart, M. (2007). Humor and social Protest: An Introduction. International Review of Social History, 52(15), 1-20. DOI: $10.1017 /$ S0020859007003094

Kuipers, G. (2008). The Sociology of Humor. In Victor Raskin \& Willibald Ruch (Eds.), The Primer of Humor Research. Berlin/New York, Mouton de Gruyter.

Laer, J. V. \& P. V. Aelst (2010). Internet and social movement action repertoires. Information, Communication \& Society, 13(8), pp. 1146-1171. Doi:

Leboeuf, M. (2007). The Power of Ridicule: An Analysis of Satire. Senior Honors Projects, 63.

Lintott, S. (2016). Superiority in Humor Theory. Journal of Aesthetics and Art Criticism, 74(4), 347-358.

Lussier, B. \& Y. Gregoire \& M. Vachon (2017). The role of humor usage on creativity, trust and performance in business relationships. An analysis of the salesperson-customer dyad. Industrial Marketing Management, 65, 168-181. Doi:

Morgan, A. (2010). Discourse analysis: An overview for the Neophyte Researcher. Journal of Health and Social Care Improvement, 1, 1-7.

Pais, J. M. (2014). De uma geração rasca a uma geração à rasca: jovens em contexto de crise. In Carrano, P., Fávero, O. (Eds.), Narrativas juvenis e espaços públicos: olhares de pesquisas em educação, mídia e ciências sociais (pp. 71-95), Niterói, Editora da UFF.

Pais, P. C. (2017). O humor em protestos de rua: as manifestações anti-austeridade como espaços de discurso (in)formal e criativo. Dissertação de Mestrado em Comunicação, Cultura e Tecnologias da Informação, Lisboa, ISCTE-IUL.

Romanos, E. (2012). The strategic use of humor in the spanish indignados/15M movement. The Politics and Protest Workshop, New York, CUNY Graduate Center.

Romanos, E. (2013). Humor in the Streets: The Spanish Indignados. Perspectives on Europe, 43(2), 15-20.

Romero E. J., \& K. W. Cruthirds (2006). The Use of Humor in the Workplace. Academy of Management Perspectives, 20(2), 58-69.

Soeiro, J. (2014). Da Geração à Rasca ao Que se Lixe a Troika. Portugal no novo ciclo internacional de protesto. Sociologia, Revista da Faculdade de Letras da Universidade do Porto, XXVIII, 55-79.

Sombatpoonsiri, J. (2015). Nonviolent action as the interplay between political contexts and 'insider's knowledge': exploring Otpor's preference for humorous protest across Serbian towns. In Kurt Schock (Ed.), Civil Resistance: Comparative Perspectives on Nonviolent Struggle. Minnesota, University of Minnesota Press.

Sørensen, M. J. (2014). Humorous Political Stunts: Nonviolent Public Challenges to Power. 
Doctor of Philosophy thesis, School of Humanities and Social Inquiry, Australia, University of Wollongong.

Speier, H. (1998). Wit and Politics: An Essay on Power and Laughter. The American Journal of Sociology, 103(5), 1352-1401.

Tabacaru, S. (2015). Uma visão geral das Teorias do Humor: aplicação da Incongruência e da Superioridade ao sarcasmo. EID\&A-Revista Eletrônica de Estudos Integrados em Discurso e Argumentação, 9, 115-136.

Tancons, C. (2014). Occupy Wall Street: Carnival Against Capital? Carnivalesque as Protest Sensibility. In Pnina Werbner \& Martin Webb \& Kathryn Spellman-Poots (Eds), The Political Aesthetics of Global Protest. The Arab Spring and Beyond (pp. 291-319). Edinburgh, Edinburgh University Press.

Touraine, A. (1985). An Introduction to the Study of Social Movements. Social Research, 52(4), 749-787.

Watson, C. (2014). A Sociologist Walks into a Bar (and Other Academic Challenges): Towards a Methodology of Humour. SAGE, 49(3), 407-421.

Pedro Caldeira Pais. Departamento de Sociologia, Escola de Sociologia e Políticas Públicas, ISCTE - Instituto Universitário de Lisboa \& Centro de Investigação e Estudos de Sociologia (CIES-IUL). Av. ${ }^{a}$ das Forças Armadas, 1649-026 Lisboa, Portugal. Email: pedromcpais@gmail.com

Rita Espanha. Departamento de Sociologia, Escola de Sociologia e Políticas Públicas, ISCTE - Instituto Universitário de Lisboa \& Centro de Investigação e Estudos de Sociologia (CIES-IUL). Av. ${ }^{a}$ das Forças Armadas, 1649-026 Lisboa, Portugal.

Email: rita.espanha@iscte-iul.pt

Data de submissão: 05/07/2018 | Data de aceitação: 12/10/2018 